\title{
UNIVERSITYOF
}

FORWARD

THINKING

WESTMINSTER用

WestminsterResearch

http://www.westminster.ac.uk/westminsterresearch

\section{Technological advances relevant to transport - understanding what drives them}

Cohen, T. and Jones, P.

NOTICE: this is the authors' version of a work that was accepted for publication in Transportation Research Part A: Policy and Practice. Changes resulting from the publishing process, such as peer review, editing, corrections, structural formatting, and other quality control mechanisms may not be reflected in this document. Changes may have been made to this work since it was submitted for publication. A definitive version was subsequently published in Transportation Research Part A: Policy and Practice, 135, pp. 80-95, 2020.

The final definitive version in Transportation Research Part A: Policy and Practice is available online at:

https://dx.doi.org/10.1016/j.tra.2020.03.002

(C) 2020. This manuscript version is made available under the CC-BY-NC-ND 4.0 license https://creativecommons.org/licenses/by-nc-nd/4.0/

The WestminsterResearch online digital archive at the University of Westminster aims to make the research output of the University available to a wider audience. Copyright and Moral Rights remain with the authors and/or copyright owners. 


\section{Technological advances relevant to transport - understanding what drives them}

Tom Cohen ${ }^{1} \&$ Peter Jones ${ }^{2}$

\section{Abstract}

Transport policy makers are increasingly perplexed by the pace of change in their sector and by the increasing influence of external actors. This leads to a variety of responses, including "business as usual", technological optimism, technological fatalism and technological ignorance. To explore this perplexity and its justification, we examine four areas of technological advance relevant to transport: mobility as a service; unmanned aerial vehicles (drones); automated vehicles; and telehealth. In each case, we identify the principal underlying shifts which are driving these technological advances, concluding that there is considerable overlap: three of the advances rely on ubiquitous sensing and on artificial intelligence and all four rely, to some degree, on connectedness. We then explore these three "drivers", finding that progress is steadier than may be generally thought. We discuss the implications for our set of transport-related technological developments, concluding that policy makers could approach the future with greater confidence than is currently typical. They could also draw on the concepts of anticipatory governance to support their management of emerging technology and, at the same time, of the influence of external actors.

\section{Highlights}

- Anxiety concerning the future can lead transport policy makers to make poor decisions

- Many technological developments relevant to transport share common underlying "drivers"

- The "drivers" of many transport-relevant technological developments are moving relatively predictably

- Transport policy makers can afford to be more confident about the future

- Anticipatory governance may aid the management of technological change

\section{Keywords}

Technology; futures; governance; MaaS; drones; AVs.

\section{Introduction}

"The ordinary 'horseless carriage' is at present a luxury for the wealthy, and altho its price will probably fall in the future, it will never, of course, come into as common use as the bicycle" (Literary Digest, 1899).

Such examples of the folly of prediction are good sport and help to promote humility in the transport planner. Just as the car must have appeared a passing fad to the author of the above statement, today's transport professionals are likely to be guilty of failing to understand how

\footnotetext{
${ }^{1}$ Corresponding author: t.cohen@westminster.ac.uk, University of Westminster, 35 Marylebone Road, London NW1 5LS, UK. orcid.org/0000-0002-3818-2087

2 peter.jones@ucl.ac.uk, UCL Centre for Transport Studies, Gower Street, London WC1E 6BT, UK
} 
technologies emerging today may be adopted and used by future generations. But the inevitability of those mistakes does not alter the fact that decisions continue to be made (and need to be made) whose lifespan exceeds the 120 years that have elapsed since the horseless carriage was discounted in the pronouncement above. Infrastructure typically lasts a long time and the need or not to build it must therefore be informed by some thought concerning travel behaviour over the decades that follow its construction. Hence the traffic forecasting industry, which uses assumptions concerning the likely path of drivers of travel demand, and their relationship with actual travel, to produce predictions long into the future. The fallibility of this process has too been exposed (Marsden, 2017).

Though decision making under uncertainty is nothing new, there is a sense that the level of uncertainty is increasing and/or that the range of possible futures is widening (Lyons and Davidson, 2016). Talk of the fourth industrial revolution (Schwab, 2017) gives weight to the notion that the world is going through a more extreme set of changes than has been typical. In the transport sector, several emerging technologies appear to have the potential to prove revolutionary: automated vehicles could alter travel behaviour profoundly and lead to economic restructuring and dramatic changes in land use; unmanned aerial vehicles (drones) may make use of aviation for both personal and goods transport routine, thereby reducing the volumes of movement on the surface network and introducing significant new challenges relating to airspace, privacy, safety and security, etc. Meanwhile, the Uber phenomenon has been humbling for many cities which have been forced to watch as large numbers of additional trips have been loaded onto their crowded road networks (Cohen, 2018).

None of these developments happens in a vacuum, of course. The technological developments take place in a social and policy context which helps to determine the path that the technology, policy makers and wider society eventually follow (Geels, 2002, 2010). Nor is the way in which these advances are thought of neutral; the hype cycle (see discussion of automated driving below) is just one representation of the way in which the facts of the technology interact with expectations and arguments surrounding it. And the power of those expectations must not be underestimated: as Borup et al, put it, "in a sense, expectations are both the cause and consequence of material scientific and technological activity" (Borup et al., 2006, p. 286). Expectations can come to prove self-fulfilling prophecies (Merton, 1948). Hype describes a tendency to have inflated expectations in the early stages concerning the technology's potential and this reminds us that, during a technology's infancy, there are various actors who stand to gain from fostering both the belief that much good will come from the technology and, of greater importance for this paper, that it is just around the corner.

These actors include those who stand to gain in material terms from adoption of the new technology as well as those whose personal brands or more strategic objectives might be thereby served. An obvious example of those who may profit are the so-called "tech unicorns" whose business models may mean that their viability depends on a certain volume of activity. It is in their interests to talk up the inevitability and immediacy of the technologies they are peddling because this will increase the likelihood that investors will choose their companies. This phenomenon is accompanied by the growth of personality cults associated with some of the more colourful business leaders in the sector, such as Elon Musk (Boyle, 2018), whose history of erroneous predictions concerning automated driving has not deterred him from continuing to make them (Hawkins, 2019).

This helps to explain the sense of immediacy which can give rise to a feeling of panic in the policy maker. And the fact that an emerging technology is "new" makes it difficult to apply the lessons of 
previous disappointments (both within and outside the sector in question), because this one "may be different" (Borup et al., 2006).

Various responses to this sense of uncertainty and decreasing influence can be detected, both passive and active. Some reactions to the predicted advent of automated vehicles can be styled as 'technological optimism' (Krier and Gillette, 1985). For example, in the USA, senators Peters and Thune brought forward legislation (the AV START act - Thune, 2017) designed to enable testing and development of the technology, based on an avowedly positive view of its potential. Senator Peters is quoted as saying "...self-driving vehicles will completely revolutionize the way we get around in the future, and it is vital that public policy keep pace with these rapidly developing lifesaving technologies that will be on our roads in a matter of years" (Peters, Thune Introduce Bipartisan Legislation to Advance Development of Self-Driving Vehicles, 2017). The reference to public policy keeping pace with the technology (rather than setting its pace) is striking. That is, instead of acknowledging the deep uncertainties associated with the technology, these lawmakers embrace its potential benefits and adopt a strategy of enabling innovators to advance the technology, with the strong conviction that good will result.

In contrast with technological optimism is technological fatalism, characterised by a supine belief that, good or bad, a technology is coming and resistance is futile (Licker, 2001). This is associated with a tendency on the part of public authorities not to attempt to intervene. A further, distinct response might be called technological ignorance: for example, Guerra's 2016 survey of American Metropolitan Planning Organisations (MPOs) found that none had included mention of the technology in their long-range planning documents. Whilst some interviewees cited unawareness or scepticism for this omission, the most prominent explanation was uncertainty about what form the technology would take and what the impacts would be (Guerra, 2016). This approach can be contrasted with discussing the technology and how it might contribute to or obstruct the achievement of the public body's objectives, perhaps extending to proposals concerning policies that could guide the technology in a positive direction. Instead, the decision to remain silent concerning automated-vehicle technology suggests that the MPOs feel they lack control over it, which links to technological fatalism.

This approach characterises much of mainstream forecasting. For example, traffic forecasting has (as previously identified) a long history of inaccuracy, in common with the vast majority of longrange forecasting worldwide. The methods used have been slightly modified over time, with the 2018 set of national forecasts for the UK based on a number of "scenarios" to represent possible variations in underlying conditions (Department for Transport, 2018). On closer examination, these "scenarios" would better be described as "sensitivities", because they represent modest departures from the central case - and do not incorporate potential major mobility disruptors. This distinction is important for two reasons: first, sensitivity tests do not test the extent of the "possibility space" as scenarios are meant to; and, second, because they are variations on a core forecast, there is a natural tendency to select the core forecast as "preferred" because it represents an average, of sorts. And, in the case of the previous set of forecasts (Department for Transport, 2015a), this is what happened (Marsden et al., 2018). That is, because planners are unable to say which of a number of variants is most likely to come about, they select the variant that best represents business as usual.

On the more pro-active side, various transport bodies have used scenario planning or other futures methods in an attempt to work constructively with the uncertainty that they face when planning for the future (Lyons and Davidson, 2016; Hickman, Ashiru and Banister, 2009; Tuominen et al., 2014). In contrast with the sensitivity tests which are a very common feature of transport forecasting and 
appraisal, scenario planning in the form developed by Shell (Wack, 1985b, 1985a) involves a deliberate attempt to describe possible futures that are very different from each other and which, as far as possible, are positioned at the extremes of what is considered plausible by stakeholders. In particular, there is no way in which one can take the "average" of a set of scenarios developed in this way, which circumvents the "central-case" problem identified above. Whilst scenario planning is a very useful planning aid, it (quite deliberately) does not produce a single answer.

We represent a range of reactions to dealing with uncertainty using Figure 1. The figure has two axes - attitude to uncertainty and level of engagement. Actors can deny uncertainty (e.g. business as usual) or embrace it (e.g. futures-based strategy development), with both technological optimism and fatalism following a middle course that represents some acceptance of uncertainty but a decided lack of enthusiasm for it (though for quite different reasons). As to engagement, technological fatalists and the technologically ignorant are passive, in contrast with technological optimists and those pursuing business as usual. Those conducting futures-based strategy development do not clearly occupy either end of this axis (see below) and hence are placed at the centre.

\section{Figure 1}

To return to the uncertainty itself, a further reason for the growing unease about how to respond to it may be less the change anticipated than the way in which it is communicated: though hype is nothing new (Linden and Fenn, 2003), the relatively large volume of information to which the public and professionals are now exposed may simply mean that they are confronted by descriptions and predictions of new challenges more often and with greater theatricality than used to be the case, when most communication took place on paper. A second possibility is the apparent suddenness of change that comes from developing technology at scale through software rather than hardware which can present transport planners with unexpected challenges. A ready example is Uber, whose aggressive business model and substantial backing have proved bigger determinants of the disruption it has brought than the relatively modest technological and incremental advances on which it is based (Cohen, 2018).

Meanwhile, transport decision makers still need to make decisions. Under an uncertainty-embracing paradigm, they seek to develop a strategy or a set of schemes that is expected to perform well against all scenarios considered, but this is a tall order. For example, a good set of transportrelevant scenarios ought to include a wide range of travel-demand outcomes, and it is not easy to see how a decision to build a major piece of infrastructure would appear sound in the context of both strong growth in and a contraction of demand. There is therefore the possibility that futuresbased strategy development will actually lead to decision paralysis as no course of action appears "future-proof". Hence, we see that none of the responses depicted in Figure 1 provides a guaranteed escape from the perils of uncertainty concerning the future.

Given uncertainty is unavoidable, there therefore remain very good reasons for trying to reduce it. And that is the motivation for this paper, which surveys four widely discussed technological advances relevant to transport and explores the more fundamental shifts underpinning them.

In doing so, we aim to make progress with the following questions, representing gaps in knowledge relating to transport policy:

- Are transport decision makers justified in feeling overwhelmed by the pace of change?

- How extensive, in fact, is the uncertainty concerning transport-relevant technological advances and where does it lie? 
- What might be a rational and responsible reaction to the situation?

As will be seen, we find that there is considerable overlap amongst the sets of fundamental shifts that lie beneath the technological advances we examine. Moreover, we find cause to believe that these fundamental shifts are moving relatively steadily and that, by association, transport-policy developers and decision makers need not be as fearful of developments such as drones or automated vehicles as they might think. And this is particularly important given Borup et al's finding that "expectations have the appearance of greater authority for those who see themselves as having little influence over the outcome of a promise" (Borup et al., 2006, p. 292). This may be a genuine example of knowledge bestowing power.

The rest of the paper is structured as follows:

- We set out our method in the next section;

- We then discuss a set of four technological advances either in the transport sector or likely significantly to affect it: mobility as a service (MaaS); UAVs (drones); automation of the driving task ("self-driving" road vehicles); and telehealth;

- Having identified in each case a set of fundamental underlying developmental "shifts", we then examine three that are common to at least three of the advances: connectedness; ubiquitous sensing; and artificial intelligence;

- Following a discussion, we conclude with recommendations for transport policy makers and for further research.

\section{Method}

Given the aim of this paper, we needed our sample of technological advances relevant to transport to be as diverse as possible, in order to reduce the risk of studying advances that, on examination, are revealed to be intrinsically quite similar. At the same time, resource limitations required us to keep the number of advances we studied quite small. We concluded that a set of four advances would be manageable in terms of resources whilst allowing for the desired degree of variety.

We initially considered a larger set of candidate advances. In addition to those chosen, we included the following transport advances:

- Dynamic road-space management

- New fuels and power systems for vehicles

- Sharing (e.g. cars, bicycles, scooters)

- Smart charging and pricing

- Hyperloop and related high-speed transport technologies

We also included the following advances with indirect relevance for transport:

- 3-D (or additive) printing

- Virtual presence

- The internet of things

- Expanding automation (e.g. domestic and care robots)

- Vertical farming

The four that were selected were perceived to offer a strong spread across a number of significant axes, as follows: 
- It seemed important to capture both "direct" transport advances and those likely to be relevant to transport. The transport theme of the research led us to select three transport advances and one transport-relevant advance.

- We wished to feature both new technology and service developments; hence two of each: automation of the driving task and UAVs (technologies); and MaaS and telehealth (services)

- We felt it important that both freight and passenger movement were well represented. MaaS is very much aimed at personal mobility (though the underlying technology could be more widely applied). Automated vehicles are being thought of in terms of both passenger and freight transport. And applications of UAVs to date have mainly not carried humans with current testing centred on goods (though passenger transport is clearly a goal of many organisations that are active in this field).

- Another familiar transport axis is urban/rural. On this front, to date there has been a focus in MaaS upon urban areas, given the concentration of transport networks and potential users in more densely populated areas. Telehealth has the potential to affect those in rural areas more than in urban areas given the relative distances involved in accessing services physically; and, where UAVs are concerned, they may prove more prominent in rural areas given the restrictions relating to over-flying densely populated areas (Levin, 2019).

A final consideration was prominence - to focus on what are perceived to be some of the major impending technological advances. Hence the selection of automation of the driving task and UAVs. If research interest may be seen as a proxy for the general attention these topics are receiving, the sharp increase in the number of relevant publications over the past few years in both cases demonstrates their salience. With respect to automated driving, Gandia et al record an average annual growth rate of 39 per cent (Gandia et al., 2019, p. 15), confirming earlier findings by Cavoli et al (2017); as to UAVs, Chauhan (2019) records over six times as many publications in the period 2008-2017 as in the preceding decade. More detailed analysis ${ }^{3}$ of the data obtained by Chauhan shows an exponential growth pattern since 2011.

Having selected these four themes, we conducted a wide-ranging literature search to identify relevant materials. Our principal source was Scopus which we searched using a range of synonyms for our selected technological advances. For example, with respect to automation of the driving task, we used the terms "self-driving", "driverless", "autonomous", "automated", "automation", "vehicle", "truck", "car", "bus", "driving", "road" and "highway". To supplement material identified using Scopus, we also used the transport-specific bibliographic database TRID. And, to widen our findings relating to telehealth, we used PubMed. Where initial search queries produced unmanageably large numbers of items, additional terms were introduced in order to arrive at a manageable set. The titles/abstracts were then used in filtering this set to find those items that were most pertinent to the topic. Recent publications were preferred to older work and review papers preferred to those reporting a single piece of work. We set out in the Appendix the terms used for the topic searches, the numbers of items returned and the results of filtering.

We believe that this approach has been satisfactory from the perspective of addressing the research questions set out in the introduction. In particular, the selection of four technological advances with the set of attributes described above gives us confidence that our findings are broadly based. We acknowledge, though, that a method based mainly on surveying the academic and grey literature is bound to have limitations: in particular, we have been constrained both by the extent and accuracy

3 Chauhan reports the search strategy used in his analysis. We replicated this and analysed the results on a yearly (rather than ten-yearly) basis. 
of what has been published to date and by our capacity to locate it. We return to these methodological concerns in the final section.

\section{Technological advances}

\section{Mobility as a Service}

Mobility as a Service (MaaS) has become a widely used term despite being only a few years old (Kubitz, 2017). Writers use it to describe a variety of transport phenomena ranging from (in its most modest form) improving journey-planning tools to (its most ambitious form) an integrated mobility system which enables the user to arrange and purchase door-to-door travel from a single provider, and to adjust their behaviour en route, in the event of service disruptions. In the latter case, the traveller may use multiple modes provided by multiple organisations; but the defining characteristic is that the user does not need to have dealings with more than one organisation or, in fact, to be aware of any others. The most optimistic version of MaaS has third parties filling gaps in the travel chain in cases whether a given provider has for some reason dropped out, or service delays require rescheduling of some parts of the journey.

Beyond this diversity of definitions, there is also a range of assumptions concerning what might motivate the provision of MaaS or what might result from it. One perspective is openly commercial (Transport Systems Catapult, 2016): by making use of redundant capacity in the network and offering a better proposition to the traveller, there is money to be made. Another perspective is centred on social good: MaaS has the potential to make sustainable transport more palatable to travellers and can therefore promote a shift away from private-car use, perhaps even towards active travel, improving road and public health conditions along the way. It might also help to reduce social exclusion among poorer population groups without access to a car. Various authors attempt to bring some structure to the debate by offering unifying sets of properties (Holmberg et al., 2016; Jittrapirom et al., 2017).

For our purposes, the basic underlying technology that will enable MaaS would be consistent across all but the least ambitious of these visions. That is, whether MaaS will achieve the goal of full integration in a given location will be a matter more of governance and private-sector behaviour than technology. With respect to describing the technological aspect, Giesecke et al (2016) offer a helpful summary of what they call the inter-operability aspects: "a) embed MaaS within intelligent traffic services (ITS); and b) apply ICT especially in the form of match-making algorithms, mobile phone apps and approaches analogue to social media" (Giesecke, Surakka and Hakonen, 2016, p. 753). The fundamental technological "ingredients" of MaaS are set out by Jittrapirom et al (2017): "devices, such as mobile computers and smartphones; a reliable mobile internet network (Wi-Fi, 3G, 4G, LTE); GPS; e-ticketing and e-payment system; database management system and integrated infrastructure of technologies (i.e. loT)" (Jittrapirom et al., 2017, p. 16).

Put another way, in order to succeed, MaaS requires each participant in the transaction (traveller, mobility provider and intermediary) to have some form of computer and to be connected with one another. A clear, up-to-date and detailed understanding of the traveller's needs and preferences is required, as is a similarly clear and detailed understanding of feasible trip segments by various modes. To enable the latter, all potential mobility providers must make available a database in a readable format of the mobility services they are able to offer, in real time. And the intermediary must have an effective algorithm that finds a combination of journey segments suited to the traveller's needs and preferences. Beyond this, there must be a means of creating a journey 
"contract", a payment structure, and a mechanism for providing relevant information to all the parties involved.

What might be the ultimate (or mature) form of MaaS? Views naturally differ on this (Giesecke, Surakka and Hakonen, 2016; Transport Systems Catapult, 2016), but one version would imply a highly fluid, largely demand-responsive transport system where all providers were in effect part of a "gig" economy. This is understandably unsettling for a public body which presides over a large amount of fixed infrastructure (the road network and, quite possibly, the rail network) and which may also manage a large part of the public-transport offer. If individual travellers will be able to flit like butterflies amongst modes and routes, this will create a significant amount of instability and hence uncertainty in terms of both predicting network performance and planning service provision. Even relatively modest reductions in passenger volumes on conventional public transport services can have a major impact on the finances of a transport authority (Topham, 2018). Thus the prospect of a mature form of market-led MaaS does present cities with some substantial questions.

However, although cities may have less control over the transport services provided and less influence over the choices made by individual travellers, they do retain (explicitly or implicitly) full control over the provision and allocation of urban road-space - so they can influence to some degree the levels of service afforded by different transport modes on the road network. For example, this can be through provision of priority lanes (e.g. for buses and cycles) and control of kerbside stopping activities. A loose analogy can be drawn between this and broadly steering the economy through control of the money supply.

\section{UAVs (drones)}

Unmanned aerial vehicles (UAVs) operate as part of unmanned aerial systems or unmanned aircraft systems (UAS), with the term UAS being more commonly used in North America (Clarke, 2014). The term "drone" is also widely used, though a distinction needs to be made between UAVs that "fly themselves" and UAVs that are remotely piloted. From the perspective of transport and logistics, interest lies in vehicles that would fly without any form of pilot, i.e. they would not have a human pilot either on board or governing the aircraft remotely. This is because human-piloted aircraft carrying people and/or freight are long established and are represented by relatively stable markets and there is little motivation to develop remotely piloted aircraft for conventional transport purposes in typical locations, not least because of the limited financial savings that would result ${ }^{4}$. We must, in passing, acknowledge that "drones" of various kinds are already being used extensively for non-transport applications, such as asset monitoring and surveying of remote locations. This is important as it reminds us that this is a relatively mature technology, compared with others we are considering.

The introduction of unpiloted aircraft could prove revolutionary for the following reasons:

- For the carriage of freight, there is potential for relatively light aircraft to move around densely populated areas to deliver items (subject to the resolution of safety concerns that currently motivate flying restrictions mentioned earlier), with a substantially lower cost base that is expected to make this an economic proposition

4 Remotely piloted aircraft are generally used where it is perceived that an on-board pilot would face unreasonable risk, because of conflict, for example. 
- For the carriage of people, various operators (see, for example, Uber, 2018) envisage introducing a personal taxi service based on unpiloted aircraft, on the basis that this would enable the traveller to avoid (road-based) congestion and thereby "beat the traffic"

Though the underlying technology may be similar for these two applications, there are some important differences. First, carrying a human passenger means designing vehicles for a much larger size of payload and minimum load than in the case of freight, where arbitrarily small and light parcels may usefully be conveyed by drone. This minimum envelope has important implications for the size, mass and therefore energy demands of such vehicles. Therefore, their application is likely to be much more limited. Second, the safety concerns associated with carrying human passengers are much greater than for freight. In the case of freight, there are issues of objects falling from the sky and an associated need to ensure that any harm would be minimised on the ground; where human passengers are concerned, the possible harm to them resulting from any accident would likely dwarf the existing concerns about the welfare of those at ground level. Nonetheless, UAVs for human passengers are being developed, with Dubai seeking to be at the forefront (Excell, 2017) of an increasingly crowded market (Tucker, 2018). Whether such services would ever become accessible to the public at scale is doubtful given the likely costs of operation; so it is sensible for now to see the freight and passenger applications as having quite different likely growth curves.

There is extensive discussion taking place on various fronts in relation to UAVs for transport: the regulatory aspects of drone flying are already proving very challenging and there have been various incidents involving interactions between these UAVs and conventional aircraft that have prompted concern and debate (Luppicini and So, 2016). In particular, the drone sightings at London's Gatwick Airport prior to Christmas 2018 have prompted detailed debate about the advantages and disadvantages associated with the arrival of this technology (Rowlatt, 2019). Another prominent research strand relates to privacy and ethics (Villasenor, 2013; Clarke, 2014) and the fact that lowflying aircraft, often equipped with cameras, have the potential to transgress (and, in time, redraw) societal norms concerning privacy. Beyond these, there is a longer-term question of whether the movement of goods and people over short distances by pilotless aircraft is desirable; we shall return to this. We note, meanwhile, that it is generally assumed drones will be electrically powered.

But our primary concern in this paper is technology and, more specifically, the technological advances on which pilotless aircraft depend. According to Anbaroğlu (2017), there are two broad challenge areas: battery life and "sense and avoid" systems. He is writing about parcel delivery, but his conclusions would apply equally (if not more so) to the transport of humans.

On battery life, he says "to ensure the economic feasibility of UAS carrying parcels, long lasting batteries are desired. In this way, maximum time would be spared for delivery and minimal time for recharging an UAS" (Anbaroğlu, 2017, p. 76). This is also an economic issue since pilotless aircraft already exist that have successfully carried parcels from point to point on a trial basis (Amazon.com Inc, 2016). But there is a dynamic relationship between location of depots and drop locations, density of customer locations, mass and size of parcel etc. that will determine whether a profitable business can operate at scale. Similar questions relate to the transport of humans and, in both cases, there are connected issues of permitted flight paths and landing/take-off points. The longer the battery life, the less "down time" the aircraft has and the greater its potential range and therefore productive capacity.

The second topic, "sense and avoid", describes the requirement for the aircraft to detect natural and man-made structures and objects and respond with appropriate avoidance manoeuvres in order to maintain minimal separation distances. In relation to UAVs, work has been done on machine vision 
(Lai, Mejias and Ford, 2011) and radar-based systems (Accardo et al., 2013) though major questions remain, in the view of Anbaroğlu (2017).

To his list of two challenges must be added that of fail-safe: aircraft must be relied upon to behave appropriately in response to emergencies including engine failure, cyber-attack, severe weather and lapses in communication. Where freight is concerned, there are justifiable worries about the risk of heavy items falling from the sky and causing injury or damage; these worries rise significantly in the case that the cargo is human. And there are associated concerns about the aircraft striking structures or other vehicles (Clarke, 2014).

To summarise, the "successful" application of pilotless aircraft to the transport of people and goods depends on a set of technological advances. One - the development of high-energy batteries - has been identified and is broadly separate from the rest, which relate to how the aircraft flies. For this to operate satisfactorily, first it requires an appropriate sensing system that provides a highly accurate picture of its location and the locations (and trajectories, where relevant) of all other relevant objects. Second, it requires an adequate decision-making system that will interpret data collected by the sensor system and pursue suitable courses of action; this system needs to extend to all imaginable emergency scenarios.

Assuming these technological hurdles can be overcome and that the raft of non-technological issues relating to pilotless aircraft can be satisfactorily resolved, there is a prospect of some uptake in both the freight and passenger sectors, though the magnitude of that uptake is hard to predict.

Nonetheless, authorities will naturally be wary of the potential effects of this uptake and would be forgiven for being nervous. Jackson likens the possible disruption resulting from this development to that perpetrated by the arrival of the automobile. He counsels "in our present period of upheaval, it behoves designers to navigate wisely around various unintended consequences of this spectacular technology" (Jackson, 2014, p. 24).

From the viewpoint of urban mobility, such developments have the potential to achieve a modal shift - to switch some passenger and freight movements from road to air - but the scale of this is uncertain (i.e. whether it would lead to a marginal or significant reduction in freight and passenger traffic on the urban road network), and might be more than offset by induced demand.

Here the scale of the take-up of UAV-based movement will depend on four factors: the performance and of the technology itself and its price, the air corridors and capacities that will be permitted over urban areas, and the adaptation of infrastructure to facilitate landings and take-offs; for example, the extent to which major office and residential towers will provide heliport-type facilities.

\section{Automation of the driving task - "self-driving" road vehicles ${ }^{5}$}

The degree of energy and effort being devoted in almost all senses to this topic is consistent with Gartner's finding that "autonomous vehicles" (another popular descriptor) had only recently passed the so-called "peak of inflated expectations" in its 2016 hype cycle (Gartner, 2016) 6 . This enthusiasm for self-driving technology is fuelled by perceptions that it could provide individual

5 The widely used SAE levels of automation (SAE International, 2016) are accompanied by a terminological discussion which makes the case for associating automation not with the vehicle but with the driving task, for that is the thing which it is proposed to automate. Hence the somewhat ponderous term in this section's heading, accompanied by a more recognisable (if technically inaccurate) alternative.

6 The 2018 version (Panetta, 2018) separates automated vehicles into three categories: Level-4 automation has crossed from the peak of inflated expectations into the "trough of disillusionment", whilst Level 5 and "flying autonomous vehicles" are both in the "innovation trigger" phase which precedes the peak of inflated expectations. 
states with enormous economic manufacturing and software services opportunities, and could bestow major societal benefits. And countries that do not embrace the opportunity now may regret it later, as their competitors reap the rewards.

Whatever the merits of these arguments, automation of the driving task is the subject of intense and widespread activity at the moment. And governments in general - and city governments, in particular - are to varying extents attempting to establish what role they would like this new technology to play within their jurisdictions. As might be expected in light of Gartner's assessment, there is at present little circumspection, one example being the UK government's uncritical stance that this technology is a good thing (Department for Transport, 2015b), though there is a growing research literature on the potential range of outcomes that can be expected, depending on the approach taken to governance.

As with the other topics dealt with here, our priority is to identify the technological hurdles to be overcome in order for the automation of the driving task to develop to a point where it can fulfil some of the expectations imposed upon it. Here, a useful starting point is provided by Shladover (2005), who divides the task into a series of layers: network, link, co-ordination and regulation. In summary:

- The network layer must limit access in order to maintain a stipulated operating speed and quickly restore full service following an incident;

- The link layer must provide a given level of capacity and limit access of vehicles so that demand remains within that capacity;

- The co-ordination layer must enable vehicles to travel efficiently in close proximity without conflict through speedy wireless communication; and

- The regulation layer must ensure individual vehicles follow their defined paths accurately and deliver an acceptable ride quality.

And Shladover envisages this being enabled by "sensor, communication, computation, and actuator technologies" (Shladover, 2005, p. 56). On closer examination, his vision of a self-driving world is based on a system closed to all except motorised vehicles with four or more wheels, whereas much recent research has been devoted to the interaction of automated vehicles with non-automated motor vehicles and with pedestrians and cyclists (Parkin et al., 2016; Geronimo et al., 2010), reflecting the fact that the typical urban highway environment is highly complex and diverse. Nevertheless, Shladover's summary of the technology required seems right: vehicles and infrastructure will need to sense and interpret their surroundings (Sun, Bebis and Miller, 2006). These are the elements of the task relating to ubiquitous sensing and artificial intelligence (discussed later). If the hoped-for network benefits are to come about, they will need to communicate with each other and with other users, compute a suitable course of action based on data gathered (González et al., 2016) and carry that course of action out. The communication element relates to the concept of connectedness which we also discuss below. Two of Shladover's terms perhaps do not reflect the current fashion: for computation, we should read artificial intelligence; and, for actuator, we should be thinking of the series of motors and hydraulics that would control the vehicle's path and speed. Whilst it is frequently asserted that automated vehicles will of necessity be electrically powered (Webb and Wilson, 2017; Wadud, MacKenzie and Leiby, 2016), an assertion with which we have some sympathy, we note that the automation of driving is compatible with many different power trains and that the electrification of the fleet is a technological advance in its own right. In contrast, whilst automated vehicles would not, strictly speaking, have to be communicating with either other vehicles or the wider environment in order to carry out the driving 
task, we see the viability of automated driving as dependent on such connectivity. At the level of the junction, for example, the very small gaps between vehicles that are thought possible with automation would only come about if each vehicle was sharing its planned trajectory with those around it. And, at the network level, a lack of communication between vehicles could lead to inefficient distributions of traffic across links as the individually optimal routes of vehicles proved collectively sub-optimal.

Whilst not strictly essential to the feasibility of automated driving, the issue of ensuring cybersecurity can certainly be seen as a central aspect of the acceptability of this technology. This theme embraces both the safety of personal data that may be shared as part of using an automated vehicle (Taeihagh and Lim, 2019), say, and the security of the system against attack by malicious actors (Axelrod, 2017). Here, the advances required are not peculiar to automated driving cybersecurity is a concern of all organisations handling sensitive data or operating systems that could do harm in the wrong hands - and progress in this area is incremental, as cyber-attackers make periodic advances in penetrating systems and their protectors respond with further layers of security.

As with pilotless aircraft, a focus on the technology ignores the plethora of other issues that are exercising researchers, including ethics and bias (Luetge, 2017; Awad et al., 2018), regulation (ITF, 2015), equity and other potential social and economic consequences (Cavoli et al., 2017). One reason cities in particular may be preoccupied by this technology is the question of what automated driving might do to travel habits and, somewhat further on, land use. On the assumption that it is a case of when, rather than if, automated driving moves on from the development and testing phase it currently occupies, the changes could be profound.

From an urban transport perspective, automated motor vehicles pose the greatest range of uncertainties for future transport planning and likely patterns of mobility. It is generally accepted that they have the potential to reduce accidents substantially and - at least in some situations increase road capacity, and to reduce unit travel costs.

Looking just at the automated private car, we need to consider potential changes in mode choice and routing patterns, but also in trip generation and trip distribution - in the latter case because the deterrent effect of high parking charges would not apply to vehicles that could drop off occupants and drive away from the area.

There are big uncertainties over the extent to which this technology might affect the balance between private car ownership and on-demand use of commercial fleets; and on the extent to which when not carrying passengers these vehicles spend their time moving around the network (contributing to congestion and energy consumption) or taking up carriageway space or private land for parking.

Before moving on to the next topic, we need to raise the concept of autonomy which could be argued to apply to both this and the previous topic, UAVs. "Autonomy" is often used interchangeably with "automation", though the latter term is preferred by the widely quoted SAE. In our interpretation, we contrast autonomy with "control". That is, a vehicle may "decide" independently on its route, time of departure etc; we would describe this as autonomy. Conversely, a vehicle may be given its path by a central control system, much as with air traffic control at present. It can be seen that this concept of autonomy/control becomes relevant at the level of multiple road/aerial vehicles. A large number of vehicles acting autonomously (as we define it) may produce sub-optimal results, as discussed in the context of connectedness, above. The point on the 
continuum between autonomy and control at which a given type of vehicle will operate will be in large part a regulatory matter.

\section{Telehealth}

We start with a definition: telehealth involves "using telecommunications technologies to support the delivery of all kinds of medical, diagnostic and treatment-related services" where the specialists are not located in the same place as the patient (Federal Communications Commission, 2014).

We select telehealth as a good representative of "teleservices", the set of services that are provided remotely with the aid of communication technology. There is nothing especially distinctive about telehealth, except that it has been extensively studied, as might be expected given the generally high standards of evaluation in the health sector, and could be expected to be widely taken up if considered a satisfactory tool by decision makers in the health sector. And, given that the vast majority of people in high-income countries receive some health services in an average year, the potential impact of telehealth on the transport network could be considerable. What is true of telehealth may not automatically apply to other teleservices but a good degree of commonality is likely.

We must immediately concede that telehealth is an umbrella term encompassing a wide range of health interventions that vary significantly in their technological demands. At one end of the spectrum might be telepsychiatry, "where consultants interact with a relatively stationary patient" (Jarvis-Selinger et al., 2008, p. 721), and which requires little more than a reliable mechanism for video conference calling. At the other end is telesurgery, where communication apparatus is supported by robotics, enabling the surgeon to carry out procedures remotely (Ellimoottil et al., 2016). Though communications technology is the one constant, the role of other elements varies with the task, sensors sometimes playing a part in enabling clinicians to assess a patient (Schiaffini et al., 2016) or in providing advance warning of an event such as heart failure. Moreover, the emergence of the "quantified self", with individuals increasingly monitoring their status and activity through devices such as smart watches (Swan, 2013), offers a path towards an increasing role in the health sector for data collected by sensors.

Telehealth has been developed, tested and, in many cases, implemented across a wide range of health fields (Broens et al., 2007), though practice varies, urology being one area of health in which only tentative steps appear to have so far been taken (Ellimoottil et al., 2016). Given that space does not permit an exhaustive assessment of the use of telehealth, we select telerehabilitation as a reasonable example: it places greater demands on technology than the most basic of interventions but does not require the sophisticated tools that support telesurgery. Telesurgery requires the patient to attend an operating theatre staffed by clinicians, the key difference from conventional surgery being that the surgical team is elsewhere. Wide uptake of telesurgery would not therefore be expected to alter significantly the number of trips that are made by patients, particularly given that surgery is ordinarily a very rare event in anyone's life, although it is likely that average trip lengths would reduce, since patients would not need to travel to reach such highly specialised health facilities.

As with our other topics, we concentrate on the technological side of telerehabilitation rather than issues of economics, acceptability, regulation and so on.

The first observation to make is that telehealth has been taking place for twenty years or more and studies of telerehabilitation date back to the early years of this century (e.g. Engbers et al., 2003). It is therefore no surprise that the perceived success or failure of the intervention has been a function 
of the gradually increasing speed, quality and reliability of communications technology, nor that the ambition of interventions trialled has also grown incrementally. Studies carried out of

telerehabilitation indicate that it is a successful method for the assessment stage (Mani et al., 2017), though it is less clear whether it is effective during the therapy phase (Grona et al., 2018). Here, the problem is the lack of sound data rather than evidence to suggest that it is ineffective. In any case, the technological aspect of telerehabilitation is not identified as a source of difficulty and "typically, patients are satisfied with the use of videoconferencing for telerehabilitation" (Grona et al., 2018, p. 344). We note that Mani et al.'s (2017) study features numerous uses of a software product called eHAB which offers an enhanced form of video-conferencing, including the scope to measure angles on screen. A significant feature is its Beyond Bandwidth Recording which enables clinicians to "obtain high definition video, audio or images of your clients regardless of the quality of the Internet link between you" (NeoRehab, no date). This is noteworthy as it demonstrates that possible deficiencies in the supporting technological infrastructure have been predicted and compensated for.

The general finding is that, as far as telerehabilitation is concerned, the required technology (videoconferencing tools and an internet connection of sufficient bandwidth and reliability) already exists. This branch of telehealth, therefore, is not hampered by the current state of the supporting technology. It seems reasonable to suggest that the scope of telerehabilitation might expand with further advances in the level of connectivity and quality of cameras, monitors etc., but the main conclusion is that the extent of this form of telehealth is limited for reasons other than technology.

Telerehabilitation is likely to require repeated interactions between clinician and patient during the recovery period so, if it is possible to remove the need for the clinician and patient to be in the same location, the cumulative trip-length reductions (and possibly mode choice changes) could be significant.

\section{Technological advances as functions of underlying changes}

We have examined in brief four areas of technological change expected to affect the transport sector, three of them being "transport" changes, and the other a change outside transport. In this section, we seek to understand what may be common to the four and to see what conclusions this allows us to draw.

In Table 1, we compare the four areas of change in terms of more fundamental technological shifts that are enabling them.

Table 1: Headline technological advances and underlying shifts

\begin{tabular}{|l|l|l|l|l|l|}
\hline \multirow{2}{*}{$\begin{array}{l}\text { Headline } \\
\text { technological } \\
\text { advance }\end{array}$} & \multicolumn{4}{|l|}{ Underlying shifts } \\
\cline { 2 - 6 } & $\begin{array}{l}\text { Ubiquitous } \\
\text { computing }\end{array}$ & $\begin{array}{l}\text { Ubiquitous } \\
\text { sensing }\end{array}$ & $\begin{array}{l}\text { Artificial } \\
\text { intelligence }\end{array}$ & Connectedness & Electrification \\
\hline MaaS & $\checkmark$ & $\checkmark$ & $\checkmark$ & $\checkmark$ & \\
\hline $\begin{array}{l}\text { UAVs } \\
\text { (drones) }\end{array}$ & & $\checkmark$ & $\checkmark$ & $\checkmark$ & $\checkmark$ \\
\hline
\end{tabular}

7 We differentiate between ubiquitous computing and connectedness as follows: the former describes a situation where computing devices are exceptionally common, such that owners of smartphones and other personal devices can readily process information in situ, as can computer-equipped appliances. Connectedness does not rely on there being a computer at each end of a connection but requires that data can readily pass between points (e.g. from a sensor to a computer). We acknowledge that MaaS, for example, requires the combination of ubiquitous computing and connectedness in order to function. 


\begin{tabular}{|l|l|l|l|l|l|}
\hline $\begin{array}{l}\text { Self-driving } \\
\text { road vehicles }\end{array}$ & & $\checkmark$ & $\checkmark$ & $\checkmark$ & \\
\hline Telehealth & $\checkmark$ & & & $\checkmark$ & \\
\hline
\end{tabular}

Though the original set of technological advances is reasonably diverse (as discussed in the section on method), there is a striking level of consistency in terms of the underlying technological shifts on which they depend. In particular, connectedness is a pre-requisite for all four, whilst ubiquitous sensing and artificial intelligence are pre-requisites for three of them. This echoes the findings of Zear et al:

"Rather the computer science engineering concepts such as Artificial Intelligence (AI), machine learning, communication, internet and many other emerging engineering and information sciences areas become the core of ITS" (Zear, Singh and Singh, 2016, p. 1).

What does it mean if a wide range of transport technological advances is being driven by a small number of more fundamental shifts? If those shifts can be understood, this may make it possible to think more calmly and clearly about the technological advances, bearing in mind the discussion in the introduction. Let us first look at the three underlying shifts that are most prominent in Table 1.

\section{Connectedness}

We define connectedness as the proportion of time that people and relevant devices are connected via the internet. Connection through the internet is a reasonable proxy for the capacity for the exchange of data/information conducive to the development and/or operation of the various technologies discussed in the previous section.

There are several components of connectedness:

- The possession of a capable device (in the case of people) or the fixed presence of one (in the case of vehicles, transport infrastructure etc.)

- Being connected at a given time - here we differentiate between the scope for connection (through having a mobile signal, for instance) which is a function of the technology, and the personal choice to connect, which will reflect preference and affordability

- The technology that enables connection - satellite signal, mobile signal, radio, Wi-Fi, Bluetooth etc., in terms of both hardware and software

It is not controversial to assert that the capabilities and/or availability of all the above phenomena are growing. In the case of the first, the number of smartphones in the world has grown for some time and is forecast to continue growing (Lunden, 2015); projections for growth of connected devices from the Internet of Things domain are similarly positive (Columbus, 2016; Gartner, 2017), though the rate of growth is understandably steeper given the comparative novelty of this area: for example, Columbus presents a set for annual figures of the number of loT devices (15.41 billion in 2015 rising to 75.44 billion in 2025) that maps reasonably well to a shallow exponential function ${ }^{8}$. This reflects a comparable growth pattern in the number of mobile subscriptions which is a reasonable proxy for being connected at a given time. The trend has notably been sublinear for the past five years and is predicted to continue to be (Jonsson and Carson, 2018, p. 6) ${ }^{9}$. And $5 \mathrm{G}$

8 Non-linear regression analysis produces a good fit for a function based on the exponential of [year increment*0.167].

9 Jonsson and Carson's plot of mobile subscriptions follows a gradually flattening line from approximately 6.8 billion in 2013, via 7.8 billion in 2017 to 8.9 billion in 2023 . 
represents a good example of ongoing advances on the technological side: it is the latest generation of mobile phone technologies, each having brought advantages over its predecessor in terms of penetration, functionality, bandwidth and/or speed (Jain, et al., 2014). But it is interesting to note that the predictions of growth are sublinear despite the advent of 5G (in the same way that growth was sublinear as TD-SCDMA first arrived and then gradually replaced GSM as the dominant technology).

All three of these trends appear smooth: there is reason to expect market saturation in the case of personal phone ownership and, at some point further into the future, a time when all objects that could carry an internet-enabled device do so. Growth can then be expected to be replaced by renewal. But there seems little prospect of boom and bust (Press, 2014). Meanwhile, taking a historical perspective when examining the development of connection technology gives a very clear picture of a rapid but incremental advance rather than a revolution.

\section{Ubiquitous sensing}

The ubiquity of sensing is coming from two sources: the proliferation of ever-smaller and cheaper sensors and the adoption of privately owned sensors as sources of shared data (Campbell et al., 2008). The first trend is leading to the inclusion of sensors in a growing number of products and elements of infrastructure. For example, the typical "smart" mobile phone now contains a microphone, camera, light meter, accelerometer, gyroscope, proximity gauge, compass and barometer. That this is possible without the phone being unaffordable is testament to the low cost of the sensors themselves, reflecting the fact that analogue measuring systems have been gradually replaced by electronic systems (Grayman, 2014). Hill (2013) uses sales of microprocessor cores (numbers of units) as a proxy for sensor sales, and reports a near-linear past growth rate which he extrapolates (based on projections obtained from the International Data Corporation) ${ }^{10}$. Examination of the annual global value of microprocessor sales over time suggests a more sublinear pattern, though deviations are partly attributable to price fluctuations (Semiconductor Industry Association, 2019, p. 2).

The second trend (the sharing of data) is much discussed from the perspectives of data misuse and hacking and associated safety from embarrassment or attack (Pew Research Center, 2017). The prior questions of data quality and compatibility (Srivastava, Abdelzaher and Szymanski, 2012) appear to have been resolved to the satisfaction of those who are developing services based on crowd-sourced data. For example, the highly successful traffic information service, Waze, relies on the aggregation of information freely provided by private individuals (Waze, 2018).

Looked at with circumspection, these trends are quite readily understood: one is a technological advance (sensors becoming smaller and cheaper) leading to a behavioural (market) response (the inclusion of growing numbers of sensors in consumer goods by manufacturers and their purchase by end users). The second is more complex as it reflects both a tendency on the part of technology companies to establish passive collection and sharing mechanisms, and a default behaviour on the part of end users to permit this, through either ignorance or unconcern. The first trend seems likely to describe a smooth curve that will, at some point, reach a maximum point. The second is less predictable given recent scandals concerning the use of personal data: it seems likely that a new equilibrium will be reached as technology companies adjust their behaviour in response to

10 Hill has sales of new microprocessor cores rising steadily from approximately seven billion units per annum in 2010 to approximately 21 billion in 2020 (Hill, 2013, p. p8) 
developing social norms and governmental constraints. But neither trend appears to have the character of either runaway growth or sudden crash.

\section{Artificial intelligence}

Of the three underlying shifts, artificial intelligence (AI) is the most difficult to survey briefly, given its immense variety. In the popular imagination, $\mathrm{Al}$ is characterised by significant news stories such as the success of AlphaGo in beating a Go grandmaster at the notoriously complex board game (Silver et al., 2017). This, combined with the repeated representation of robots (benign or malicious) in film and television, creates a sense that $\mathrm{Al}$ is advancing at a bewildering rate and that humans will experience its full dramatic effects in the form of redundancy (as Al takes over many jobs currently done by people) or worse, in the near future (Srnicek and Williams, 2015; Frase, 2016). Alongside these, perhaps popular, concerns about Al are more evidence-based worries about the scope for systems based on machine learning to display implicit (and presumably unintentional) bias with potentially unwelcome equity impacts (Corbett-Davies et al., 2017; Lee, 2018).

A very different picture emerges from the sector itself. For example, a text on one branch of $\mathrm{Al}$ - the design of intelligent computational agents - presents a measured view of progress to date. It lists a range of aspects of intelligent computation, grading complexity for each and asserting "the dimension that adds the most difficulty to building an agent is sensing uncertainty" (Poole and Mackworth, 2017, p. 627). This admittedly arbitrary example is helpful in drawing our attention to the size of the Al task and the extent of it that remains so far unaccomplished. A historical perspective on automated driving is also helpful in this respect: Wetmore's 2003 survey makes its point very effectively through its title, in describing 60 years of automated highway systems (Wetmore, 2003). It goes on to discuss the steady and modest technological advances that have taken place over that time.

In light of the breadth of $\mathrm{Al}$, it is useful to turn to another specific example: speech recognition. Like automated driving, this too has a long history (Pieraccini, 2017), with activity dating back to at least the 1950s. The apparent smoothness or jerkiness of its progress is a matter of scale: at close hand, setbacks such as withdrawal of research funding or advances such as the adoption in the last decade of deep learning seem significant discontinuities, the latter bringing considerable improvements in the accuracy of word recognition, for example. Markoff (2012) quotes Microsoft's Rashid as saying that this was "the most dramatic change in accuracy" since 1979. This both accentuates the size of the improvement and offers some perspective, since events in 1979 must have also seemed a discontinuity. From further out, occasional leaps in performance will blend into a steadier graph of progress: in its earliest form, speech recognition worked with only a tiny vocabulary and with gaps deliberately left between words. The vocabulary has gradually increased as has the technology's capacity to deal with a multiplicity of speaking styles and fluent, as opposed to separated, speech. As Juang and Rabiner $(2004$, p. 1) put it, the problem of automatic speech recognition "has been approached progressively". And there is some way still to go.

\section{Discussion}

The evidence from our analysis is that some prominent technological advances, directly or indirectly relevant to transport, are being driven (or facilitated) by more fundamental, non-transport technological developments that are progressing relatively steadily. If this is the case, what does it imply for the embattled policy- or decision-maker whose situation we discussed in the introduction?

Is it likely, for example, that the first-order impacts (e.g. transport technological advances) of steady fundamental shifts (e.g. ubiquitous sensing) will display less steadiness? It is certainly possible. 
Indeed, so-called tipping points are a paradigm case of dramatic change arising from seemingly steady underlying changes (Gladwell, 2002). A recent transport example is the electric scooters that have arrived in such numbers on the streets of many cities, in some cases in a very short space of time. On closer examination, though, it is quite clear that this proliferation is a result not of technological advance (the technology having been available for some years), but of a combination of entrepreneurial behaviour by providers, an accepting attitude on the part of authorities (or perceived lack of leverage), and adoption by consumers. And this is a key conclusion from our analysis: abrupt change seems likelier to arise from behavioural responses than from technological advance itself.

Though we have found reason to conclude that three fundamental shifts underlying technological advances relevant to transport are proceeding relatively smoothly, this does not entitle us to assume this would always be the case. We must therefore ask what could be expected if the fundamental shifts were jerkier. The answer is that we could definitely expect first-order impacts to mirror this character at least or, quite possibly, amplify it. Here, the message of this paper is that there is in any case value in looking at the shifts that underlie some of the more prominent transport changes in order to arrive at a more circumspect position concerning them, even if the conclusion is less reassuring than the one we have been able to draw about the three we have examined. Not only does this offer the prospect of managing the sense of unease that is widely felt amongst transport policy- and decision-makers; it also may provide them with an opportunity to anticipate coming changes.

\section{The pace of change itself}

Having examined some specific examples, we turn now to the issue of whether change itself is happening at an increasing pace (Toffler, 1973). This seemingly banal question is not irrelevant if a perception that the pace of change is quickening creates anxiety, because anxiety may foster hasty and/or injudicious decisions or equally lead to decision paralysis.

Various thinkers, notably Kurzweil (2001), have advanced arguments that change is exponential, rather than linear. In Kurzweil's case, Moore's law is used as the basis for this assertion: if semiconductors display exponential growth in speed, might this also be true of various associated development processes? This could well reflect a distinction in the rates of development between slower, more linear growth in the production and modification of complex hardware-based products and the rapid speed at which software-based developments can take place - as Elon Musk is finding in his efforts to ramp up physical car production at anything like the rates at which new software producers can grow markets. But this is not a question which we need to answer here. From the transport planner's perspective, what matters is the successful management of change, whether or not its pace is increasing. What our analysis above does suggest, though, is that the pace of change is not accelerating consistently; rather, we detect several examples of steady change. Perhaps the assertion that the pace of change is increasing is itself an instance of the hype phenomenon detected in the case of individual technological advances. If so, our analysis may be a useful counterweight to the anxiety described above.

\section{Governance in a changing environment}

Though not central to this paper, we mention here the developing field of anticipatory governance (Guston, 2014). This term is used to describe the management in advance by public bodies of emerging technologies and it is relevant because of the perceived mismatch between the rate of change in authorities' operating environments and the speed at which they are generally able to plan and implement their interventions. Moreover, decision makers naturally shrink from action in a 
situation of uncertainty, for the understandable reason that they will be subject to criticism if they are subsequently shown to have made incorrect assumptions about the future. But the example of Uber provides ample evidence that it is very difficult to achieve desired policy outcomes by regulating in retrospect (Cohen, 2018), so authorities may feel "damned if they do and damned if they don't".

Whilst the analysis in this paper suggests that transport planners may be able to narrow the range of uncertainty confronting them by looking beneath relevant emerging technologies at underlying shifts, this hardly removes completely the problem of uncertainty. So the suite of tools associated with anticipatory governance, notably experimental, time-limited and/or flexible regulation (Gersen, 2007; Ranchordás, 2013), may prove of real value. By implementing policies relatively rapidly and without the expectation of permanence, public bodies may find that they can be more "agile" in dealing with changes in their operating environments. This would provide a second way of managing the anxiety described in this paper, complementing the development of a more measured view concerning the process of change itself.

\section{Conclusion and recommendations}

Having analysed four carefully selected technological advances relevant to transport, we then examined a set of three underlying technological shifts common to several of them. We found reason to conclude that those underlying shifts are proceeding relatively smoothly and that there is no reason in the case of any of them to expect precipitous change. The implication is that abrupt change, if and when it does occur, is likelier to arise from behavioural (especially entrepreneurial) responses to technology than from the technology itself.

We posed three research questions in our introduction:

- Are transport decision makers justified in feeling overwhelmed by the pace of change?

- How extensive, in fact, is the uncertainty concerning transport-relevant technological advances and where does it lie?

- What might be a rational and responsible reaction to the situation?

Our answer to the first is that transport decision makers may be justified in feeling overwhelmed but that this may lie more in the perceived pace than the real pace of change. This leads to our answers to the second: that uncertainty concerning transport-relevant technological advances may not be as extensive as feared and that uncertainty relates more to the behavioural response to technology than to the technology itself.

We address the third question below in our recommendations to policy makers, after which we suggest directions for further research.

\section{Recommendations to policy makers}

We recommend transport policy makers confronted by a given technological advance start by trying to do as we have done, and seek out the more fundamental shifts underlying that advance. Doing so may offer some reassurance about the nature and pace of change; even if it does not, it may nevertheless provide the policy makers with some confidence concerning the nature of the challenge they face, thereby diminishing the sense of powerlessness discussed in our introduction.

Given our finding that behavioural responses to technological advance are likelier to precipitate abrupt change than the technological advance itself, it is helpful to think methodically and inclusively about the range of actors whose behaviour can affect the policy maker's operating environment. 
Having pointed out earlier that scenario planning cannot tell the policy maker whether to build or not, we nonetheless argue that it can be a powerful way of creating a coherent picture of the policy maker's extent of control and of the major forces that lie outside it. This is achieved, in part, by creating a map of the policy maker's "transactional" and "contextual" environments (Van der Heijden, 1996) and studying the possible range of developments over which she/he has no significant influence (contextual environment). This leads to a consideration of potential courses of action lying within the transactional environment by which the policy maker may expect to exert influence over events. Such an exercise naturally embraces both technological progress and behavioural responses to it, as well as other "exogenous" developments such as climate change, immigration etc. Recalling our discussion of the varying extents to which policy makers engage with uncertainty, scenario planning constitutes very active engagement and, whilst it therefore does quite the opposite of narrowing the range of possible futures, it can instead reduce the anxiety felt by the policy maker: having developed and used scenarios, the policy maker has not increased her/his influence but she/he has thought calmly and methodically about the actions available for responding to unfolding events - and should have an idea of the robustness of decisions that are taken.

Another tool available to policy makers in this context is systems thinking and, more specifically, soft systems methodology (Checkland, 1999, 2001; Checkland and Poulter, 2006). This too provides a framework for methodical analysis of the world within which the policy maker is working and, in particular, the relationships between relevant actors and phenomena. Checkland's method involves developing so-called "rich pictures" as a way of visualising these relationships.

Both scenario-based planning and soft systems methodology can be seen as tools of anticipatory governance, in that they assist the policy maker in confronting pragmatically an uncertain future. Common to both is a thorough assessment of the interventions available to policy makers, including those that have not been tried before or are not "standard practice". Here, it is worth restating our finding that technological advances are likely to be less abrupt than the behavioural responses to them and renewing our assertion that policy makers are better equipped to manage behaviour than technology.

We conclude our recommendations to policy makers by returning to our discussion of the automation of driving and the role of expected economic benefits in determining policy-maker behaviour. One important component of the reflection involved in conducting exercises such as soft systems methodology is a degree of introspection. Such introspection should enable the policy maker to understand the extent to which an attitude to a given technology is being influenced by the "fear of missing out". We freely concede that there may be real gains to be made by embracing a technology but we also urge policy makers to be alive to hype and to assess critically all claims made, in light of the consistent tendency for the long-run impacts of technologies to fall short of what was claimed for them in their infancy.

\section{Recommendations for further research}

Given the limited scope of this exercise and the imperfect measures used (namely proxies such as numbers of semi-conductors), it is desirable to conduct a fuller inquiry that addresses a larger set of transport-relevant technological advances and does so in greater depth, in order to test the robustness of our findings and to understand whether the pattern we detected is more widespread. The literature-review approach could be complemented by interviews with acknowledged experts in relevant fields in order to establish whether they agree with our trajectory analysis. 
A complementary activity would put these findings to the test with policy makers. They could be asked whether they find our conclusions (or the conclusions of a fuller study) plausible.

Alternatively, or in addition, the degree of unease they feel with respect to the future could be tracked: a before-and-after survey could be used, for example, to capture any movement in their attitudes following exposure to the findings.

\section{Declaration of author interests}

The authors have no competing interests to declare.

\section{Funding statement}

This paper builds on work done as part of CREATE project, which received funding from the European Union's Horizon 2020 Research and Innovation Programme under grant agreement No 636573.

\section{References}

Accardo, D. et al. (2013) 'Flight Test of a Radar-Based Tracking System for UAS Sense and Avoid', IEEE Transactions on Aerospace and Electronic Systems, 49(2), pp. 1139-1160. doi: 10.1109/TAES.2013.6494404.

Amazon.com Inc (2016) Amazon Prime Air. Available at: https://www.amazon.com/Amazon-PrimeAir/b?ie=UTF8\&node=8037720011 (Accessed: 3 July 2018).

Anbaroğlu, B. (2017) 'Parcel delivery in an urban environment using unmanned aerial systems: a vision paper', in ISPRS Annals of Photogrammetry, Remote Sensing and Spatial Information Sciences. WG IV/1<br>4th International GeoAdvances Workshop \&ndash; GeoAdvances 2017: ISPRS Workshop on Multi-dimensional \& Multi-scale Spatial Data Modeling (Volume IV-4/W4) - 14\&ndash;15 October 2017, Safranbolu, Karabuk, Turkey, Copernicus GmbH, pp. 73-79. doi: https://doi.org/10.5194/isprsannals-IV-4-W4-73-2017.

Awad, E. et al. (2018) 'The Moral Machine experiment', Nature. doi: 10.1038/s41586-018-0637-6.

Axelrod, C. W. (2017) 'Cybersecurity in the age of autonomous vehicles, intelligent traffic controls and pervasive transportation networks', in 2017 IEEE Long Island Systems, Applications and Technology Conference (LISAT). 2017 IEEE Long Island Systems, Applications and Technology Conference (LISAT), pp. 1-6. doi: 10.1109/LISAT.2017.8001966.

Borup, M. et al. (2006) 'The sociology of expectations in science and technology', Technology Analysis \& Strategic Management, 18(3-4), pp. 285-298. doi: 10.1080/09537320600777002.

Boyle, R. (2018) 'Elon Musk, Tesla, and NASA - Cult of personality?', Electropak, 9 July. Available at: https://electropak.net/blog/engineering/elon-musk-cult-personality/ (Accessed: 19 November 2019).

Broens, T. H. F. et al. (2007) 'Determinants of successful telemedicine implementations: a literature study', Journal of Telemedicine and Telecare, 13(6), pp. 303-309. doi:

$10.1258 / 135763307781644951$.

Campbell, A. T. et al. (2008) 'The Rise of People-Centric Sensing', IEEE Internet Computing; Los Alamitos, 12(4), pp. 12-21. doi: 10.1109/MIC.2008.90. 
Cavoli, C. et al. (2017) Social and behavioural questions associated with Automated Vehicles. A Literature Review. London: Department for Transport. Available at:

https://www.gov.uk/government/uploads/system/uploads/attachment_data/file/578943/socialand-behavioural-questions-associated-with-automated-vehicles-literature-review.pdf (Accessed: 3 June 2019).

Chauhan, S. K. (2019) 'Scholarly Output on Drone Research: A Bibliometric Study', DESIDOC Journal of Library \& Information Technology, 39(2), pp. 117-124. doi: 10.14429/djlit.39.2.13970.

Checkland, P. (1999) Systems Thinking, Systems Practice (incluldes Soft systems methodology: a 30year retrospective). Chichester: Wiley.

Checkland, P. (2001) 'Soft systems methodology', in Rosenhead, J. and Mingers, J. (eds) Rational Analysis for a Problematic World Revisited: Problem Structuring Methods for Complexity, Uncertainty and Conflict. 2nd Edition. John Wiley \& Sons, pp. 61-89.

Checkland, P. and Poulter, J. (2006) Learning for action: a short definitive account of soft systems methodology and its use for practitioner, teachers, and students. Chichester: Wiley.

Clarke, R. (2014) 'Understanding the drone epidemic', Computer Law \& Security Review, 30(3), pp. 230-246. doi: 10.1016/j.clsr.2014.03.002.

Cohen, T. (2018) 'Being ready for the next Uber: can local government reinvent itself?', in Proceedings of 7th Transport Research Arena TRA 2018, April 16-19, 2018, Vienna, Austria. Transport Research Arena, Vienna.

Columbus, L. (2016) Roundup Of Internet Of Things Forecasts And Market Estimates, 2016, Forbes. Available at: https://www.forbes.com/sites/louiscolumbus/2016/11/27/roundup-of-internet-ofthings-forecasts-and-market-estimates-2016/ (Accessed: 16 July 2018).

Corbett-Davies, S. et al. (2017) 'Algorithmic decision making and the cost of fairness', arXiv:1701.08230 [cs, stat]. doi: 10.1145/3097983.309809.

Department for Transport (2015a) Road Traffic Forecasts 2015. London: Department for Transport. Available at:

https://www.gov.uk/government/uploads/system/uploads/attachment_data/file/411471/roadtraffic-forecasts-2015.pdf (Accessed: 20 July 2018).

Department for Transport (2015b) 'The Pathway to Driverless Cars Summary report and action plan'. DfT Publications. Available at:

https://www.gov.uk/government/uploads/system/uploads/attachment_data/file/401562/pathwaydriverless-cars-summary.pdf (Accessed: 3 July 2018).

Department for Transport (2018) Road Traffic Forecasts 2018. London: Department for Transport. Available at: https://www.gov.uk/government/publications/road-traffic-forecasts-2018 (Accessed: 19 September 2018).

Ellimoottil, C. et al. (2016) 'Telemedicine in Urology: State of the Art', Urology, 94, pp. 10-16. doi: 10.1016/j.urology.2016.02.061.

Engbers, L. et al. (2003) 'Development of a teleconsultation system for communication between physiotherapists concerning children with complex movement and postural disorders', Journal of Telemedicine and Telecare, 9(6), pp. 339-343. doi: 10.1258/135763303771005243. 
Excell, J. (2017) 'Autonomous air taxi trials commence in skies above Dubai', The Engineer, 28 September. Available at: https://www.theengineer.co.uk/dubai-begins-autonomous-air-taxi-trials/ (Accessed: 19 November 2019).

Federal Communications Commission (2014) Telehealth, Telemedicine and Telecare: What's What?, Federal Communications Commission. Available at: https://www.fcc.gov/general/telehealthtelemedicine-and-telecare-whats-what (Accessed: 4 July 2018).

Frase, P. (2016) Four futures: visions of the world after capitalism. London: New York : Verso.

Gandia, R. M. et al. (2019) 'Autonomous vehicles: scientometric and bibliometric review', Transport Reviews, 39(1), pp. 9-28. doi: 10.1080/01441647.2018.1518937.

Gartner (2016) Gartner's 2016 Hype Cycle for Emerging Technologies Identifies Three Key Trends That Organizations Must Track to Gain Competitive Advantage. Available at: http://www.gartner.com/newsroom/id/3412017 (Accessed: 26 September 2017).

Gartner (2017) Gartner Says 8.4 Billion Connected 'Things' Will Be in Use in 2017, Up 31 Percent From 2016. Available at: https://www.gartner.com/newsroom/id/3598917 (Accessed: 16 July 2018).

Geels, F. W. (2002) 'Technological transitions as evolutionary reconfiguration processes: a multi-level perspective and a case-study', Research policy, 31(8), pp. 1257-1274.

Geels, F. W. (2010) 'Ontologies, socio-technical transitions (to sustainability), and the multi-level perspective', Research Policy. (Special Section on Innovation and Sustainability Transitions), 39(4), pp. 495-510. doi: 10.1016/j.respol.2010.01.022.

Geronimo, D. et al. (2010) 'Survey of Pedestrian Detection for Advanced Driver Assistance Systems', IEEE Transactions on Pattern Analysis and Machine Intelligence, 32(7), pp. 1239-1258. doi: 10.1109/TPAMI.2009.122.

Gersen, J. E. (2007) 'Temporary Legislation', The University of Chicago Law Review; Chicago, 74(1), pp. 247-298.

Giesecke, R., Surakka, T. and Hakonen, M. (2016) 'Conceptualising Mobility as a Service A User Centric View on Key Issues of Mobility Services', in. 2016 Eleventh International Conference on Ecological Vehicles and Renewable Energies (EVER), Monte Carlo: IEEE, pp. 744-755. Available at: http://ieeexplore.ieee.org/servlet/opac?punumber=7469653 (Accessed: 29 June 2018).

Gladwell, M. (2002) The tipping point: how little things can make a big difference. London: Abacus.

González, D. et al. (2016) 'A Review of Motion Planning Techniques for Automated Vehicles', IEEE Transactions on Intelligent Transportation Systems, 17(4), pp. 1135-1145. doi: 10.1109/TITS.2015.2498841.

Grayman, W. M. (2014) 'Ubiquitous Sensing: Potential and Pitfalls', World Environmental and Water Resources Congress 2014. (Proceedings). doi: 10.1061/9780784413548.084.

Grona, S. L. et al. (2018) 'Use of videoconferencing for physical therapy in people with musculoskeletal conditions: A systematic review', Journal of Telemedicine and Telecare, 24(5), pp. 341-355. doi: 10.1177/1357633X17700781. 
Guerra, E. (2016) 'Planning for Cars That Drive Themselves: Metropolitan Planning Organizations, Regional Transportation Plans, and Autonomous Vehicles', Journal of Planning Education and Research, 36(2), pp. 210-224. doi: 10.1177/0739456X15613591.

Guston, D. H. (2014) 'Understanding "anticipatory governance”', Social Studies of Science, 44(2), pp. 218-242. doi: 10.1177/0306312713508669.

Hawkins, A. J. (2019) Here are Elon Musk's wildest predictions about Tesla's self-driving cars, The Verge. Available at: https://www.theverge.com/2019/4/22/18510828/tesla-elon-musk-autonomyday-investor-comments-self-driving-cars-predictions (Accessed: 19 November 2019).

Hickman, R., Ashiru, O. and Banister, D. (2009) 'Achieving Carbon-Efficient Transportation: Backcasting from London', Transportation Research Record, 2139(1), pp. 172-182. doi: 10.3141/2139-20.

Hill, D. J. (2013) 'Ubiquitous and Crowdsourced Sensing: A New Paradigm for Environmental Monitoring', EWRI Currents, Volume 15(Number 3), pp. 8-9.

Holmberg, P.-E. et al. (2016) MOBILITY AS A SERVICE- MAAS Describing the framework 2016-01-15. Stockholm: Victoria Swedish ICT AB. Available at:

https://www.viktoria.se/sites/default/files/pub/www.viktoria.se/upload/publications/final_report_ maas_framework_v_1_0.pdf (Accessed: 29 June 2018).

ITF (2015) Automated and Autonomous Driving. Regulation under uncertainty. Paris: International Transport Forum, OECD. Available at: http://www.itf-

oecd.org/sites/default/files/docs/15cpb_autonomousdriving.pdf.

Jackson, P. P. (2014) 'Game of drones', Architectural Review, 236(1410), pp. 22-24.

Jain, V. S. et al. (2014) 'Overview on Generations of Network: 1G,2G,3G,4G,5G', Int.J.Computer Technology \& Applications, 5(5), pp. 1789-1794.

Jarvis-Selinger, S. et al. (2008) 'Clinical Telehealth Across the Disciplines: Lessons Learned', Telemedicine and e-Health, 14(7), pp. 720-725. doi: 10.1089/tmj.2007.0108.

Jittrapirom, P. et al. (2017) 'Mobility as a Service: A Critical Review of Definitions, Assessments of Schemes, and Key Challenges', Urban Planning, 2(2), pp. 13-25. doi: 10.17645/up.v2i2.931.

Jonsson, P. and Carson, S. (eds) (2018) Ericsson Mobility Report. Stockholm: Ericsson. Available at: https://www.ericsson.com/en/mobility-report/reports/november-2018 (Accessed: 22 January 2019).

Juang, B. H. and Rabiner, L. R. (2004) 'Automatic Speech Recognition - A Brief History of the Technology Development'. Available at:

http://www.ece.ucsb.edu/Faculty/Rabiner/ece259/Reprints/354_LALI-ASRHistory-final-10-8.pdf (Accessed: 16 July 2018).

Krier, J. E. and Gillette, C. P. (1985) 'The Un-Easy Case for Technological Optimism', Michigan Law Review, 84(3), pp. 405-429. doi: 10.2307/1289008.

Kubitz, B. (2017) Mobility as a Service: multiple visions of a brave new world. Available at: https://www.transportxtra.com/publications/local-transport-today/news/54365/mobility-as-aservice-multiple-visions-of-a-brave-new-world/ (Accessed: 5 October 2017). 
Kurzweil, R. (2001) The Law of Accelerating Returns. Available at: http://www.kurzweilai.net/thelaw-of-accelerating-returns (Accessed: 26 June 2018).

Lai, J., Mejias, L. and Ford, J. J. (2011) 'Airborne vision-based collision-detection system', Journal of Field Robotics, 28(2), pp. 137-157. doi: 10.1002/rob.20359.

Lee, N. T. (2018) 'Detecting racial bias in algorithms and machine learning', Journal of Information Communication \& Ethics in Society, 16(3), pp. 252-260. doi: 10.1108/JICES-06-2018-0056.

Levin, I. (2019) U.S. Plan Could Permit Drone Flights Over Crowds, Claims Journal. Available at: https://www.claimsjournal.com/news/national/2019/01/15/288727.htm (Accessed: 3 June 2019).

Licker, P. (2001) 'A Gift from the Gods? Components of Information Technological Fatalism, Determinism in Several Cultures'. Available at:

http://www.sba.oakland.edu/Faculty/licker/Personal/Research/Output/Presentations/GIFTGOD.DO C (Accessed: 17 May 2018).

Linden and Fenn (2003) Understanding Gartner's Hype Cycles. Available at:

http://www.bus.umich.edu/KresgePublic/Journals/Gartner/research/115200/115274/115274.html (Accessed: 26 June 2018).

Literary Digest (1899) 'The automobile bicycle', 14 October, p. 463.

Luetge, C. (2017) 'The German Ethics Code for Automated and Connected Driving', Philosophy \& Technology, 30(4), pp. 547-558. doi: 10.1007/s13347-017-0284-0.

Lunden, I. (2015) '6.1B Smartphone Users Globally By 2020, Overtaking Basic Fixed Phone Subscriptions', TechCrunch, 3 June. Available at: http://social.techcrunch.com/2015/06/02/6-1bsmartphone-users-globally-by-2020-overtaking-basic-fixed-phone-subscriptions/ (Accessed: 16 July 2018).

Luppicini, R. and So, A. (2016) 'A technoethical review of commercial drone use in the context of governance, ethics, and privacy', Technology in Society, 46, pp. 109-119. doi: 10.1016/j.techsoc.2016.03.003.

Lyons, G. and Davidson, C. (2016) 'Guidance for transport planning and policymaking in the face of an uncertain future', Transportation Research Part A: Policy and Practice, 88, pp. 104-116. doi: 10.1016/j.tra.2016.03.012.

Mani, S. et al. (2017) 'Validity and reliability of Internet-based physiotherapy assessment for musculoskeletal disorders: a systematic review', Journal of Telemedicine and Telecare, 23(3), pp. 379-391. doi: 10.1177/1357633X16642369.

Markoff, J. (2012) 'Scientists See Advances in Deep Learning, a Part of Artificial Intelligence', The New York Times, 23 November. Available at:

https://www.nytimes.com/2012/11/24/science/scientists-see-advances-in-deep-learning-a-part-ofartificial-intelligence.html (Accessed: 16 July 2018).

Marsden, G. (2017) '“Prediction is very difficult, especially if it's about the future"', drgregmarsden, 16 January. Available at: https://drgregmarsden.wordpress.com/2017/01/16/prediction-is-verydifficult-especially-if-its-about-the-future/ (Accessed: 22 January 2019).

Marsden, G. et al. (2018) ALL CHANGE? The future of travel demand and the implications for policy and planning. First Report of the Commission on Travel Demand. Available at: 
http://www.demand.ac.uk/wp-content/uploads/2018/04/FutureTravel_report_final.pdf (Accessed: 19 July 2018).

Merton, R. K. (1948) 'The Self-Fulfilling Prophecy', The Antioch Review, 8(2), pp. 193-210. doi: $10.2307 / 4609267$.

NeoRehab (no date) 'Telerehabilitation for Physiotherapist'. Available at: http://www.neorehab.com/for-providers/telerehabilitation-for-physiotherapist/ (Accessed: 4 July 2018).

Panetta, K. (2018) 5 Trends Emerge in the Gartner Hype Cycle for Emerging Technologies, 2018. Available at: https://www.gartner.com/smarterwithgartner/5-trends-emerge-in-gartner-hype-cyclefor-emerging-technologies-2018/ (Accessed: 22 January 2019).

Parkin, J. et al. (2016) Understanding interactions between autonomous vehicles and other road users: A literature review. Technical Report. University of the West of England, Bristol, UK. Available at:

http://eprints.uwe.ac.uk/29153/1/UWE\%20autonomous\%20vehicle\%20interactions\%20literature\% 20review\%20June\%202016.pdf (Accessed: 13 October 2016).

Peters, Thune Introduce Bipartisan Legislation to Advance Development of Self-Driving Vehicles (2017) U.S. Senator Gary Peters of Michigan. Available at:

https://www.peters.senate.gov/newsroom/press-releases/peters-thune-introduce-bipartisanlegislation-to-advance-development-of-self-driving-vehicles (Accessed: 19 July 2018).

Pew Research Center (2017) Americans and Cybersecurity. Washington, DC: Pew Research Center. Available at: http://www.pewinternet.org/wp-content/uploads/sites/9/2017/01/Americans-andCyber-Security-final.pdf (Accessed: 23 January 2019).

Pieraccini, R. (2017) The Voice in the Machine: Building Computers That Understand Speech. MIT Press.

Poole, D. L. and Mackworth, A. K. (2017) Artificial Intelligence: Foundations of Computational Agents. 2 edition. Cambridge New York, NY Port Melbourne Daryaganij, Delhi Singapore: Cambridge University Press. Available at: http://artint.info/2e/html/ArtInt2e.html (Accessed: 26 June 2018).

Press, G. (2014) Internet of Things By The Numbers: Market Estimates And Forecasts, Forbes. Available at: https://www.forbes.com/sites/gilpress/2014/08/22/internet-of-things-by-thenumbers-market-estimates-and-forecasts/ (Accessed: 16 July 2018).

Ranchordás, S. (2013) 'The Whys and Woes of Experimental Legislation', The Theory and Practice of Legislation, 1(3), pp. 415-440. doi: 10.5235/2050-8840.1.3.415.

Rowlatt, J. (2019) 'Gatwick drone pilot "could be insider"', BBC News, 14 April. Available at: https://www.bbc.com/news/uk-47919680 (Accessed: 3 May 2019).

SAE International (2016) Taxonomy and Definitions for Terms Related to Driving Automation Systems for On-Road Motor Vehicles. J3016. Warrendale, PA: SAE International. Available at: http://standards.sae.org/j3016_201609/(Accessed: 23 November 2016).

Schiaffini, R. et al. (2016) 'Impact of long-term use of eHealth systems in adolescents with type 1 diabetes treated with sensor-augmented pump therapy', Journal of Telemedicine and Telecare, 22(5), pp. 277-281. doi: 10.1177/1357633X15598425. 
Schwab, K. (2017) The Fourth Industrial Revolution. 01 edition. New York: Portfolio Penguin.

Semiconductor Industry Association (2019) 2019 Factbook. Washington DC: Semiconductor Industry Association. Available at: https://www.semiconductors.org/resources/2019-sia-factbook/ (Accessed: 5 June 2019).

Shladover, S. E. (2005) 'Automated vehicles for highway operations (automated highway systems)', Proceedings of the Institution of Mechanical Engineers, Part I: Journal of Systems and Control Engineering, 219(1), pp. 53-75. doi: 10.1243/095440705X9407.

Silver, D. et al. (2017) 'Mastering the game of Go without human knowledge', Nature, 550(7676), pp. 354-359. doi: 10.1038/nature24270.

Srivastava, M., Abdelzaher, T. and Szymanski, B. (2012) 'Human-centric sensing', Phil. Trans. R. Soc. A, 370(1958), pp. 176-197. doi: 10.1098/rsta.2011.0244.

Srnicek, N. and Williams, A. (2015) Inventing the future: postcapitalism and a world without work. Brooklyn, NY: Verso Books.

Sun, Z., Bebis, G. and Miller, R. (2006) 'On-road vehicle detection: a review', IEEE Transactions on Pattern Analysis and Machine Intelligence, 28(5), pp. 694-711. doi: 10.1109/TPAMI.2006.104.

Swan, M. (2013) 'THE QUANTIFIED SELF: Fundamental Disruption in Big Data Science and Biological Discovery', Big Data, 1(2), pp. 85-99. doi: 10.1089/big.2012.0002.

Taeihagh, A. and Lim, H. S. M. (2019) 'Governing autonomous vehicles: emerging responses for safety, liability, privacy, cybersecurity, and industry risks', Transport Reviews, 39(1), pp. 103-128. doi: 10.1080/01441647.2018.1494640.

Thune, J. (2017) S.1885 - 115th Congress (2017-2018): AV START Act. Available at: https://www.congress.gov/bill/115th-congress/senate-bill/1885 (Accessed: 22 January 2019).

Toffler, A. (1973) Future Shock. New edition edition. London: Pan Books.

Topham, G. (2018) 'TfL facing near f1bn deficit next year after journey numbers fall', The Guardian, 12 February. Available at: http://www.theguardian.com/uk-news/2018/feb/12/fall-in-journeysleaves-tfl-facing-near-1bn-deficit-next-year (Accessed: 29 June 2018).

Transport Systems Catapult (2016) MOBILITY AS A SERVICE EXPLORING THE OPPORTUNITY FOR MOBILITY AS A SERVICE IN THE UK. Available at: https://ts.catapult.org.uk/intelligent-mobility/imresources/maasreport/.

Tucker, I. (2018) 'Air taxis: we have lift-off...', The Guardian, 4 March. Available at:

https://www.theguardian.com/technology/2018/mar/04/air-taxis-we-have-lift-off-airbus-vahanaehang-volocopter-uber-elevate-lilium (Accessed: 19 November 2019).

Tuominen, A. et al. (2014) 'Pluralistic backcasting: Integrating multiple visions with policy packages for transport climate policy', Futures, 60, pp. 41-58. doi: 10.1016/j.futures.2014.04.014.

Uber (2018) Uber Elevate / Summit 2018, uber.com. Available at: https://www.uber.com/elevate/summit/ (Accessed: 2 July 2018).

Van der Heijden, K. (1996) Scenarios: the art of strategic conversation. Chichester, England; New York: John Wiley \& Sons. 
Villasenor, J. (2013) 'Observations from Above: Unmanned Aircraft Systems and Privacy', Harvard Journal of Law and Public Policy; Cambridge, 36(2), pp. 457-517.

Wack, P. (1985a) 'Scenarios: shooting the rapids', Harvard Business Review, (November), pp. 139150.

Wack, P. (1985b) 'Scenarios: uncharted waters ahead', Harvard Business Review, pp. 73-89.

Wadud, Z., MacKenzie, D. and Leiby, P. (2016) 'Help or hindrance? The travel, energy and carbon impact of highly automated vehicles', Transportation Research Part A: Policy and Practice, 86(10.1016/j.tra.2015.12.001), pp. 1-18.

Waze (2018) Free Community-based GPS, Maps \& Traffic Navigation App. Available at: https://www.waze.com/about (Accessed: 16 July 2018).

Webb, J. and Wilson, C. (2017) 'Powering the Driverless Electric Car of the Future', in Sioshansi, F. P. (ed.) Innovation and Disruption at the Grid's Edge. Academic Press, pp. 101-122. doi: 10.1016/B9780-12-811758-3.00006-1.

Wetmore, J. M. (2003) 'Driving the Dream. The History and Motivations Behind 60 Years of Automated Highway Systems in America', Automotive History Review, (Summer 2003 (40)), pp. 4-19.

Zear, A., Singh, P. K. and Singh, Y. (2016) 'Intelligent Transport System: A Progressive Review', Indian Journal of Science and Technology, 9(32). doi: 10.17485/ijst/2016/v9i32/100713.

\section{Appendix}

In this appendix we provide a brief summary of the search strategies used to identify relevant sources for our investigation of the sample of the four technological advances.

\section{Mobility as a service}

A search using Scopus for documents whose title included the phrase "mobility as a service" $O R$ maas returned 406 items. A similar search in TRID returned 90 items. The titles/abstracts of the most recent 100 from the aggregated set were examined to identify the most relevant sources: 18 documents were then examined in detail.

\section{UAVs (drones)}

A search using Scopus for documents whose title included the phrase "unmanned aerial system" OR "unmanned aerial vehicle" OR uas OR uav OR drone returned 28,998 items. These numbers being unmanageable given available resources, a more targeted search was conducted by adding the string enabl* OR technolog* OR operational* (also associated with item title) with the intention of finding documents that discussed the practicalities of the technology. This returned 880 items. A similar search in TRID returned 44 items. The titles/abstracts of the 100 most recent items from the aggregated set were then examined to identify the most relevant sources: 21 documents were then examined in detail.

\section{Automation of the driving task - "self-driving" road vehicles}

Scopus was searched for documents whose title included (self-driving OR driverless $O R$ autonomous $O R$ automated $O R$ automation) $A N D$ (vehicle $O R$ truck $O R$ car $O R$ bus $O R$ driving $O R$ road $O R$ highway) AND (enabl* OR technolog* OR operational*). This produced 377 items. A similar search in TRID produced 200 records. The most recent 100 items from the aggregated set were examined and the 16 most relevant items then studied in detail. 


\section{Telehealth}

A search using Scopus for documents whose title included the word telehealth returned 2,658 items. A similar search in PubMed returned 2,162 items. These numbers being unmanageable given available resources, a more targeted search was conducted by adding the string "enab/* $O R$ technolog* OR operational*" (also associated with item title) with the intention of finding documents that discussed the practicalities of telehealth. This returned 203 documents in Scopus and 138 in PubMed. The most recent 100 of the aggregated set were then examined and the resulting 12 were assessed in detail. The reference lists from the most pertinent items of that set were then used to find additional key sources.

Once we had decided that telerehabilitation was a suitable sub-topic for more detailed examination, we conducted similar searches, replacing telehealth with telerehabilitation. With the additional string "enabl* OR technolog* OR operational*", this produced 27 items in Scopus and 21 in PubMed. Again, these sets were aggregated and filtered for relevance, producing a set of eight.

\section{Figures}

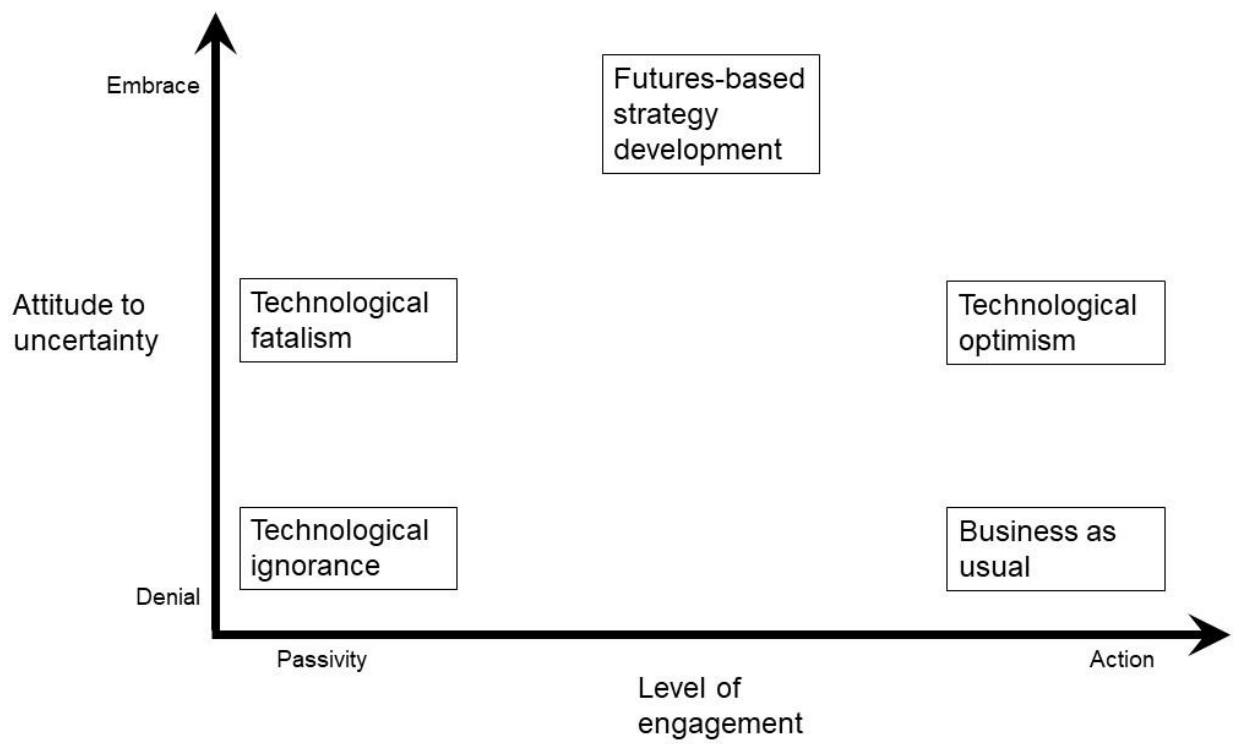

Figure 1: Reactions to uncertainty about the future 